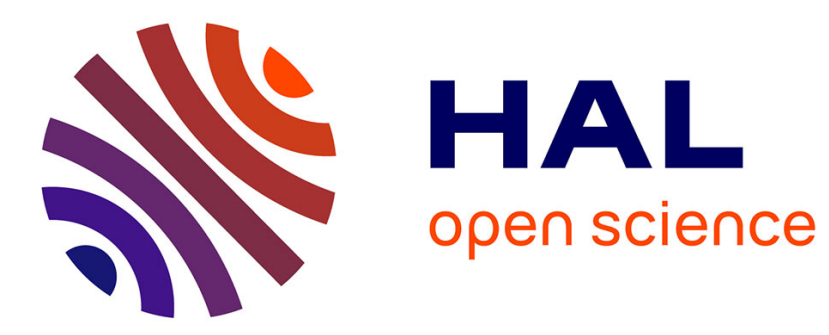

\title{
Full-circle Eulerian cradle for low temperature neutron investigations
}

\author{
F. Elf, G. Will, J. Chatzipetros, B. Dujka
}

\section{To cite this version:}

F. Elf, G. Will, J. Chatzipetros, B. Dujka. Full-circle Eulerian cradle for low temperature neutron investigations. Revue de Physique Appliquée, 1984, 19 (9), pp.793-794. 10.1051/rphysap:01984001909079300 . jpa-00245262

\section{HAL Id: jpa-00245262 https://hal.science/jpa-00245262}

Submitted on 1 Jan 1984

HAL is a multi-disciplinary open access archive for the deposit and dissemination of scientific research documents, whether they are published or not. The documents may come from teaching and research institutions in France or abroad, or from public or private research centers.
L'archive ouverte pluridisciplinaire HAL, est destinée au dépôt et à la diffusion de documents scientifiques de niveau recherche, publiés ou non, émanant des établissements d'enseignement et de recherche français ou étrangers, des laboratoires publics ou privés. 


\title{
Full-circle Eulerian cradle for low temperature neutron investigations
}

\author{
F. Elf, G. Will \\ Mineralogisches Institut der Universität Bonn, Arbeitsgruppe Neutronenbeugung in KFA Jülich, \\ Poppelsdorfer Schloß, D-5300 Bonn, F.R.G. \\ J. Chatzipetros and B. Dujka \\ Technische Dienste (TD-MW), Kernforschungsanlage Jülich, D-5170 Jülich, F.R.G.
}

\begin{abstract}
Résumé. - Un berceau Eulérien à cercle entier a été développé pour des études de diffraction neutronique par des monocristaux à basses températures $(2 \mathrm{~K}<T<300 \mathrm{~K})$. L'appareil avec deux moteurs pas à pas est monté complètement dans un cryostat d'hélium. Un pas pour l'angle chi est équivalent à une rotation de $0,005^{\circ}$ et pour $l^{\prime}$ angle phi à une rotation de $0,01^{\circ}$, ce qui permet un positionnement de $0,01^{\circ}$ en chi et $0,02^{\circ}$ en phi avec une reproductibilité du même ordre.
\end{abstract}

\begin{abstract}
A full-circle Eulerian cradle has been developed for single crystal neutron diffraction investigations at low temperatures $(2 \mathrm{~K}<T<300 \mathrm{~K})$. The device including two stepping motors is mounted completely inside the sample room of a helium cryostat. One step of the chi- and phi-motors is equivalent to a rotation of $0.005^{\circ}$ in chi and $0.01^{\circ}$ in phi, permitting a positioning within $0.01^{\circ}$ in chi and $0.02^{\circ}$ in phi with a reproducibility in the same range.
\end{abstract}

\section{Introduction.}

In X-ray and neutron diffraction analysis Eulerian cradles are standard instruments for single crystal studies. Two alternative technologies are thinkable when such cradles shall be used at very low temperatures. The one technology, which is used quite common today, is based on rather large circles, which permit to hold and move various cryostats or refrigerator systems on the cradle. All rotations take place at room temperature with the disadvantage of mechanical vibrations or movable transfer tubes. The alternative approach is to move the whole crystal unit with all circles into the cryostat. We have developed and constructed such an Eulerian cradle.

\section{Mechanics.}

There are three essential difficulties for the low temperature technology to overcome : the material experiences brittleness and contraction on cooling, wet lubrication cannot be used and we need a suitable operation of the stepping motors.

In our device the two circles are made of red brass, produced by centrifugal casting process. This material should be free of tension or stress thus minimizing distortion and anisotropic thermal contraction. In order to reduce friction the worm wheels and worm shafts are made of red brass and beryllium copper bronze, resp. Additionally, the teeth are covered with gliding varnish (Molykote $321 \mathrm{R}$ ). The material of the ball bearings of the stepping motors and worm shafts and the balls of the two circles is beryllium copper. The rotor of the stepping motors is plated with nickel to avoid rust. The electrical wires are coated with low temperature resistant and flexible insulation. Special housings around the chi- and phi-circle are provided for suitable movement of the supply wires (see photo).

A photograph of the Eulerian cradle is shown in figure 1 . The inner radius of the chi-circle is $87 \mathrm{~mm}$. Provision is made for mounting goniometer heads up to $52 \mathrm{~mm}$ height with ACA standard threads.

The phi- and chi-rotations are performed by two identical stepping motors. One motor step results in a rotation of $1.8^{\circ}$. Two worm gears provide a transmission ratio of $1: 360$ for the chi- and $1: 180$ for the phi-rotation; thus one chi-step corresponds to $0.005^{\circ}$ and one phi-step to $0.01^{\circ}$. The positioning accuracy lies within $0.01^{\circ}$ in chi and $0.02^{\circ}$ in phi, which has been verified by a measured reproducibility in the same range. The zero position for the $360^{\circ}$ rotations of both circles is marked by microswitches. 


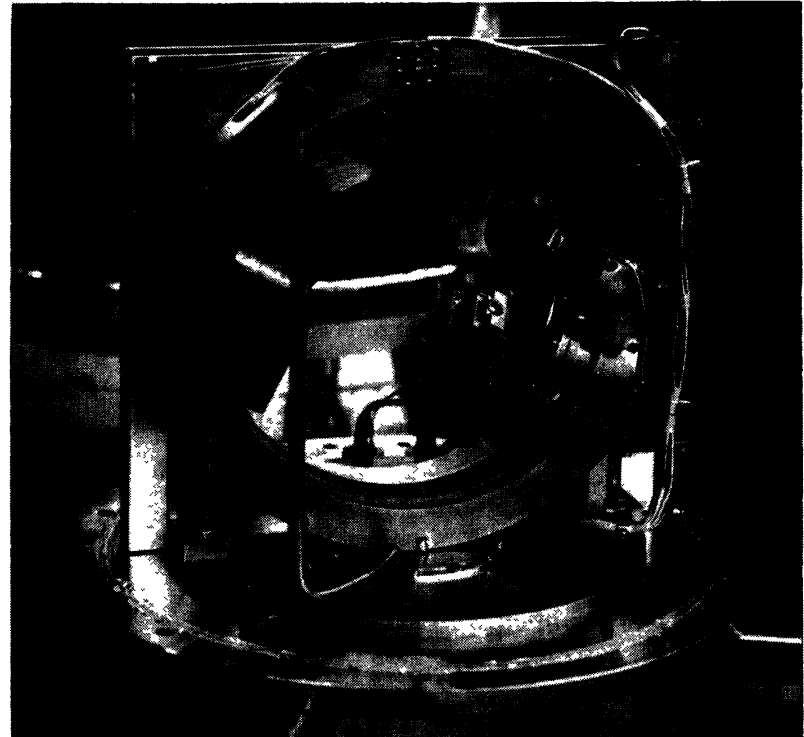

Fig. 1. - Photograph of the Eulerian cradle mounted on the base of the low temperature chamber of the cryostat.

\section{Cryostat.}

The configuration of the Eulerian cradle within the cryostat is depicted in figure 2 . The sample chamber with a volume of about 151 is located under the helium reservoir of the cryostat (capacity about 251 ). Helium reservoir and sample chamber are connected by a capillary tube (item 6 of Fig. 2). The flow of liquid helium through the capillary is regulated by a needle valve. Wires for heating. which allow us to obtain well-defined temperatures between $2 \mathrm{~K}$ and $300 \mathrm{~K}$, are wound around the bottom part of the sample container. Two cryogenic linear temperature sensors (CLTS) are installed at the lower and upper part of the chi circle. The cryostat is equipped with $\mathrm{Al}$ neutron windows of $20 \mathrm{~mm}$ height around the sample container, the radiation and vacuum shields. Additionally, on one side of the cryostat there is a glass window of $46 \mathrm{~mm}$ diameter for optical observation and laser adjustments of the sample crystal inside the cryostat. This window may also be used for an in situ irradiation of the crystal by a laser at low temperatures.

\section{Performance test.}

So far, the device has been tested in the cryogenic laboratory outside the reactor hall. In order to minimize helium consumption and to secure slow and uniform cooling of the mechanics the cryostat was precooled slowly with liquid nitrogen. The chamber was filled with liquid helium, which was maintained at a level of about $3 \mathrm{~cm}$ below the sample crystal as it will be the case during the neutron diffraction measurements. During a performance test at $4.2 \mathrm{~K}$ the mechanics of the Eulerian cradle was operated for

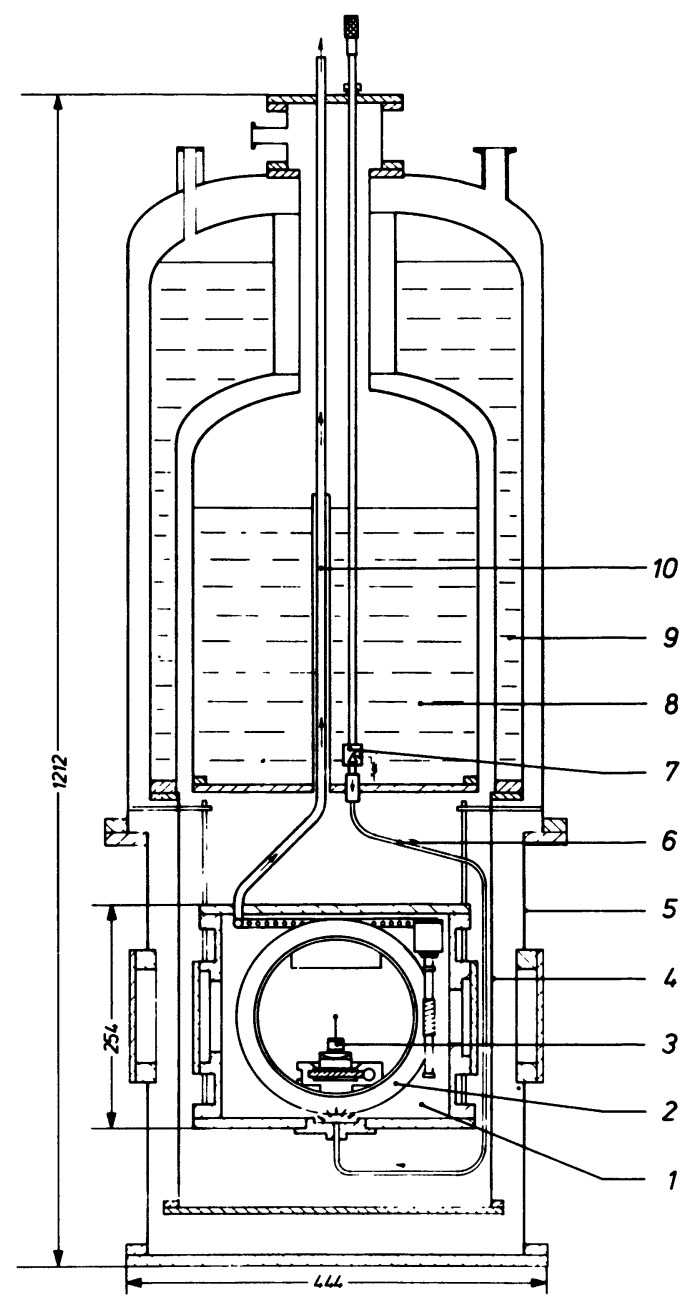

Fig. 2. - Schematic representation of the Eulerian cradle inside the helium cryostat. 1 : chamber for Eulerian cradle, 2 : Eulerian cradle (chi-circle), 3 : goniometer head, 4 : radiation shield, 5 : vacuum shield, 6 : capillary tube for helium transfer to the sample chamber, $7:$ needle valve for temperature regulation, $8:$ liquid helium reservoir, 9 : liquid nitrogen reservoir, $10:$ helium exhaust.

about 2 days without any irregularities. A similar test run had been performed earlier with liquid nitrogen for several days. The movements of the chi- and phi-circle have been optically controlled through the glass window. The precision of the stepwidth rotations has been verified by laser beam reflections at a mirror in the sample position. In the near future the device will be installed on the diffractometer Nancy in the DIDO research reactor in Jülich.

\section{Acknowledgments.}

Especial thanks are due to Dr. W. Schäfer and R. Skowronek for constructive and useful advice and stimulating discussion. Financial support by the Bundesministerium für Forschung und Technologie, Bonn is gratefully acknowledged. 